\title{
Stock Market Integration Between Three CEECs
}

\author{
Guglielmo Maria Caporale
}

Brunel University, London

\author{
Nicola Spagnolo \\ Brunel University, London
}

\begin{abstract}
This paper estimates a trivariate VAR-GARCH $(1,1)$ model to examine volatility linkages between the stock markets of three Central and Eastern European countries (CEECs), namely the Czech Republic, Hungary and Poland. The empirical findings suggest that following the EU accession regional linkages have become even stronger, and that therefore portfolio diversification within the region has become an even less effective investment strategy. This can be plausibly interpreted as reflecting deeper integration with the "old" EU economies, and has important implications for appropriate policy responses to shocks originating in those countries and affecting the financial stability of the CEECs.
\end{abstract}

- JEL Classification: C32, F36, G15

- Keywords: Central and Eastern European Countries (CEECs), Volatility Spillovers, VAR-GARCH Model

\footnotetext{
*Corresponding address: Guglielmo Maria Caporale; Centre for Empirical Finance, Brunel University, West London, UB8 3PH, UK. Tel.: +44 1895266 713; fax: +44 1895269 770. E-mail: GuglielmoMaria.Caporale@brunel.ac.uk. / Nicola Spagnolo; Centre for Empirical Finance, Brunel University, West London, UB8 3PH, UK. Tel.: +44 1895266 366; fax: +44 1895269 770. E-mail: nicola.spagnolo (a)brunel.ac.uk

(C)2012-Center for Economic Integration, Sejong Institution, Sejong University, All Rights Reserved.
} 


\section{Introduction}

This paper estimates a tri-variate VAR-GARCH $(1,1)$ model to examine linkages between the equity markets of three Central and Eastern European countries (CEECs), namely the Czech Republic, Hungary, and Poland. These three particular CEECs were chosen as the ones having the highest market capitalisation in the region. Moreover, as pointed out by Hanousek and Kocenda (2011), all three of them have a substantial presence of EU investors in their stock markets (and strong trade links with the rest of the EU), which makes them particularly susceptible to financial spillovers (as well as the effects of macroeconomic news announcements) from the developed EU countries. Therefore, an interesting issue to investigate is whether, following their accession into the EU in May 2004, linkages between these three CEECs have become even stronger, which could be interpreted as the result of deeper integration with the "old" EU economies, with developments in those countries becoming an even more important common factor driving stock markets in the CEECs.

The degree of integration of financial markets is obviously an important topic owing to its implication for portfolio management strategies as well as financial stability. Although several empirical investigations have been carried out, only a few of them estimate GARCH models and distinguish clearly between interdependence and contagion (see, e.g., Egert and Kocenda, 2007, 2011). Another exception is a recent study (see Caporale and Spagnolo, 2011) adopting a VAR-GARCH framework which is suitable to analyse interdependence by estimating volatility spillovers, and also possible shifts in the transmission of volatility following the EU accession in order to test for contagion (as defined in Caporale et al., 2005). This was used to examine bilateral linkages between the CEECs and two countries outside the region, namely the UK and Russia, and evidence of stronger linkages with the UK in particular was found following the EU accession. As already mentioned, the present study focuses instead on linkages within Central and Eastern Europe itself, and asks the question whether spillovers within the region have increased after the EU accession, possibly as a result of a higher degree of integration with the rest of the EU and a stronger common influence of the "old" EU members. ${ }^{1}$ The layout of the paper is the following.

\footnotetext{
${ }^{1} \mathrm{~A}$ related but separate issue is how asset prices in these stock markets react to macroeconomic announcements. Hanousek et al. (2009) find a significant impact of EU-wide and US ones in the case of Hungary and the Czech Republic respectively, whilst only a marginal effect of EU news on the Polish market is detected. Buttner et al. (2011) report that over time there has been an increasing influence of EU news relative to US ones in all three CEECs under consideration.
} 
Section II outlines the econometric modelling approach. Section III describes the data and presents the empirical findings. Section IV summarises the main .findings and offers some concluding remarks.

\section{The Model}

We model the joint process governing stock market return indices for the Czech Republic, Hungary and Poland using a tri-variate VAR-GARCH(1,1) framework. ${ }^{2}$ The model has the following specification:

$$
x_{t}=\alpha+\beta x_{t-1}+\gamma z_{t-1}+\delta f_{t-1}+\mathrm{u}_{t}
$$

where $x_{t}=\left(H_{u n}, C_{z R e p}, P_{t}\right)$ stands for each of the three country indices in turn. We control for monetary policy shocks by including in the mean equation the domestic 3-month interest rate, $\mathrm{f}_{t-1}=\left(\right.$ HunInt $_{\mathrm{t}-1}, \mathrm{CzInt}_{\mathrm{t}-1}$, PolInt $\left.\mathrm{t}_{\mathrm{t}-1}\right)$. Furthermore, exogenous shocks measured by US stock market returns, $z_{t-1}=\left(\right.$ USret $\left._{t-1}\right)$, are also included as a proxy for market globalisation. The residual vector $u_{t}=\left(e_{1 t}, e_{2 t}, e_{3 t}\right)$ is tri-variate and normally distributed $\mathrm{u}_{\mathrm{t}} \mid \mathrm{I}_{\mathrm{t}-1} \sim\left(0, \mathrm{H}_{\mathrm{t}}\right)$ with its corresponding conditional variance covariance matrix given by:

$$
H_{t}=\left[\begin{array}{l}
h_{11, t}, h_{12, t}, h_{3, t} \\
h_{21, t}, h_{22, t}, h_{23, t} \\
h_{31, t}, h_{32, t}, h_{33, t}
\end{array}\right]
$$

The parameter vector of the mean return equation (1) is defined by the constant $\alpha=\left(\alpha_{11}, \alpha_{22}, \alpha_{33}\right)$, the autoregressive term, $\beta=\left(\beta_{11}, 0,0\left|0, \beta_{22}, 0\right| 0,0, \beta_{33}\right)$, the monetary policy variable $\delta=\left(\delta_{11}, 0,0\left|0, \delta_{22}, 0\right| 0,0, \delta_{33}\right)$ and the market globalisation variable $\gamma=\left(\gamma_{11}\left|\gamma_{22}\right| \gamma_{33}\right)$. The parameter matrices for the variance Equation (2) are defined as $\mathrm{C}_{0}$, which is restricted to be upper triangular, and two unrestricted matrices $A_{11}$ and $G_{11}$ : The possible effects of the EU accession (May 2004) are captured by including a dummy variable (denoted by *) to model the shift in the transmission of volatility between stock markets (i.e., contagion). Therefore, the second moment will take the following form:

\footnotetext{
${ }^{2}$ The model is based on the GARCH(1,1)-BEKK representation proposed by Engle and Kroner (1995).
} 


$$
\mathrm{H}_{\mathrm{t}}=\mathrm{C}_{0} \mathrm{C}_{0}+\mathrm{A}_{11}{ }_{11}\left[\mathrm{u}_{\mathrm{t}-1} \mathrm{u}_{\mathrm{t}-1}\right] \mathrm{A}_{11}+\mathrm{G}_{11}{ }_{11} \mathrm{H}_{\mathrm{t}-1} \mathrm{G}_{11}
$$

where

$$
A_{11}=\left[\begin{array}{ccc}
a_{11} & a_{12}+a_{12}^{*} & a_{13}+a_{13}^{*} \\
a_{21}+a_{21}^{*} & a_{22} & a_{23}+a_{23}^{*} \\
a_{31}+a_{31}^{*} & a_{32}+a_{32}^{*} & a_{33}
\end{array}\right] ; \quad G_{11}=\left[\begin{array}{lcc}
g_{11} & g_{12}+g_{12}^{*} & g_{13}+g_{13}^{*} \\
g_{21}+g_{21}^{*} & g_{22} & g_{23}+g_{23}^{*} \\
g_{31}+g_{31}^{*} & g_{32}+g_{32}^{*} & g_{33}
\end{array}\right]
$$

Equation (3) models the dynamic process of $\mathrm{H}_{t}$ as a function of its own past values $\mathrm{H}_{\mathrm{t}-1}$ and of past values of innovations $\left(\mathrm{e}_{1, \mathrm{t}-1}, \mathrm{e}_{2, \mathrm{t}-1}, \mathrm{e}_{3, \mathrm{t}-1}\right)$, allowing for ownmarket and cross-market influences in the conditional variances. The BEKK model guarantees by construction that the covariance matrix in the system is positive definite.

\section{Empirical Results}

We use weekly data (from Datastream) for the Czech Republic, Hungary and Poland. Furthermore, we control for monetary policy and stock market globalisation using domestic interest rates (the 3-month Treasury Bill interest rate) and a proxy for the global stock market index (US stock market index) over the period 12/1/1996 - 12/3/2008, for a total of 614 observations. The three CEECs under investigation have the biggest financial markets by market capitalisation in the region. We define weekly returns as logarithmic differences of stock indices. Weekly data are chosen to overcome the problem of asynchronous trading (with the US) which is present in the case of daily data and would bias some of the results. In order to test the adequacy of the models, Ljung.Box portmanteau tests were performed on the standardised and squared residuals. Overall, the results indicate that the VAR-GARCH $(1,1)$ specification captures satisfactorily the persistence in returns and squared returns of all the three series considered. ${ }^{3}$ The estimated own-market conditional variance coefficients are statistically significant and the estimates of g11 suggest a high degree of persistence. Cross- market dependence in variance varies in magnitude and sign across countries. The estimated VAR-GARCH $(1,1)$ model with associated robust standard errors and likelihood function values are presented in Table 1.

\footnotetext{
${ }^{3}$ Note that the sign in cross-market volatilities are not relevant.
} 
Table 1. Estimated VAR-GARCH(1,1) model.

\begin{tabular}{|c|c|c|c|c|c|}
\hline & Coefficient & S.E. & & Coefficient & S.E. \\
\hline & \multicolumn{5}{|c|}{ Conditional Mean Equation } \\
\hline$\alpha_{1}$ & 0.0066 & $(0.0012)$ & $\beta_{11}$ & 0.0445 & $(0.0162)$ \\
\hline$\alpha_{2}$ & 0.0072 & $(0.0013)$ & $\beta_{22}$ & 0.0157 & $(0.0032)$ \\
\hline$\alpha_{3}$ & 0.0051 & $(0.0007)$ & $\beta_{33}$ & 0.0035 & $(0.0022)$ \\
\hline$\gamma_{11}$ & 0.1213 & $(0.0534)$ & $\delta_{11}$ & -0.0011 & $(0.0004)$ \\
\hline$\gamma_{22}$ & 0.1015 & $(0.0432)$ & $\delta_{22}$ & -0.0003 & $(0.0001)$ \\
\hline \multirow[t]{2}{*}{$\gamma_{33}$} & 0.1612 & $(0.0788)$ & $\delta_{33}$ & -0.0003 & $(0.0001)$ \\
\hline & \multicolumn{5}{|c|}{ Conditional Variance Equation } \\
\hline $\mathrm{c}_{11}$ & -0.0066 & $(0.0023)$ & $\mathrm{c}_{22}$ & 0.0011 & $(0.0002)$ \\
\hline $\mathrm{c}_{12}$ & 0.0050 & $(0.0021)$ & & & \\
\hline $\mathrm{g}_{11}$ & 0.4909 & $(0.0735)$ & $a_{11}$ & -0.1467 & $(0.0724)$ \\
\hline $\mathrm{g}_{22}$ & -0.8168 & $(0.4121)$ & $a_{11}$ & -0.0503 & $(0.0268)$ \\
\hline $\mathrm{g}_{33}$ & 0.9221 & $(0.0124)$ & $a_{11}$ & 0.0622 & $(0.0132)$ \\
\hline \multicolumn{6}{|c|}{ Czeck Republic $\rightarrow$ Hungary } \\
\hline $\mathrm{g}_{21}$ & -0.8730 & $(0.0401)$ & $\mathrm{a}_{21}$ & -0.0546 & $(0.0210)$ \\
\hline $\mathrm{g} * 21$ & 0.3615 & $(0.1576)$ & $a^{*}{ }_{21}$ & 2.6806 & $(0.5337)$ \\
\hline \multicolumn{6}{|c|}{ Hungary $\rightarrow$ Czeck Republic } \\
\hline $\mathrm{g}_{12}$ & 0.9285 & $(0.0461)$ & $a_{12}$ & 0.1871 & $(0.0802)$ \\
\hline $\mathrm{g} * 12$ & -0.4674 & $(0.0727)$ & $\mathrm{a}^{*}{ }_{12}$ & 0.0892 & $(0.0409)$ \\
\hline \multicolumn{6}{|c|}{ Hungary $\rightarrow$ Poland } \\
\hline $\mathrm{g}_{13}$ & -0.1144 & $(0.0024)$ & $\mathrm{a}_{13}$ & 0.0994 & $(0.0445)$ \\
\hline $\mathrm{g}^{*}{ }_{13}$ & 0.2657 & $(0.0608)$ & $a^{*}{ }_{13}$ & -0.0410 & $(0.0205)$ \\
\hline \multicolumn{6}{|c|}{ Poland $\rightarrow$ Hungary } \\
\hline $\mathrm{g}_{31}$ & 0.9225 & $(0.0572)$ & $a_{31}$ & 0.1754 & $(0.0848)$ \\
\hline $\mathrm{g} *_{31}$ & -0.6990 & $(0.1069)$ & $a^{*}{ }_{31}$ & & \\
\hline \multicolumn{6}{|c|}{ Czeck Republic $\rightarrow$ Poland } \\
\hline $\mathrm{g}_{23}$ & 0.2234 & $(0.0059)$ & $a_{23}$ & -0.1897 & $(0.0135)$ \\
\hline $\mathrm{g} *_{23}$ & -0.8253 & $(0.1506)$ & $a^{*}{ }_{23}$ & 0.6815 & $(0.1938)$ \\
\hline \multicolumn{6}{|c|}{ Poland $\rightarrow$ Czeck Republic } \\
\hline $\mathrm{g}_{32}$ & & & $a_{32}$ & & \\
\hline $\mathrm{g} *_{32}$ & & & $a *{ }_{32}$ & & \\
\hline LogLik & 4533.24 & & & & \\
\hline $\mathrm{LB}_{\text {Hun,(5) }}$ & 10.3421 & $\mathrm{LB}_{\text {CzRep,(5) }}$ & 8.9322 & $\mathrm{LB}_{\text {Pol, (5) }}$ & 8.4675 \\
\hline $\mathrm{LB}_{\text {Hun,(5) }}^{2}$ & 8.9221 & $\mathrm{LB}_{\text {CzRep,(5) }}^{2}$ & 7.2213 & $\mathrm{LB}_{\mathrm{Pol},(5)}^{2}$ & 6.4472 \\
\hline
\end{tabular}

Note: Standard errors (S.E.) are calculated using the quasi-maximum likelihood method of Bollerslev and Wooldridge (1992), which is robust to the distribution of the underlying residuals. All parameters reported are statistically significant at $5 \% . \mathrm{LB}_{(5)}$ and $\mathrm{LB}_{(5)}{ }_{(5)}$ are respectively the Ljung-Box test (1978) of significance of autocorrelations of five lags in the standardized and standardized squared residuals for Hungary, the Czech Republic and Poland. The covariance stationary condition is satisfied by all the estimated models, all the eigenvalues of $A_{11} \otimes A_{11}+G_{11} \otimes G_{11}$ being less than one in modulus. Note that in the conditional variance equation the sign of parameters is not relevant. Note that in the conditional variance equation the sign of the parameters is not relevant. 
Wald tests are performed to test two sets of null hypotheses: (i) no volatility spillovers before the EU accession (interdependence); (ii) no shift in volatility spillovers after the EU accession (contagion). The tests statistics imply a rejection of the null hypothesis of no volatility spillovers (interdependence) for all countries but from Poland into Hungary $\left(\mathrm{a}_{32}=\mathrm{g}_{32}=0\right)$. Moreover, there is evidence of contagion post $\mathrm{EU}$ accession with the null of no shift being rejected in all cases but one $\left(\mathrm{a}^{*}{ }_{32}=\mathrm{g}^{*}{ }_{32}=0\right)$.

The results reported in Table 1 suggest the following. ${ }^{4}$ First, the coefficient (in absolute value) is largest for the spillovers from Hungary to the Czech Republic, being equal to 0.1871, and from the Czech Republic to Poland, $\mathrm{a}_{32}=-0.1897$. Interestingly, the spillover effects increase after the EU accession. In particular, volatility in the stock market of the Czech Republic seems to affect strongly the markets in Hungary and Poland, the corresponding coefficients being equal to $2.635\left(\mathrm{a}_{21}+\mathrm{a}_{21}\right)$ and $0.8712\left(\mathrm{a}_{23}+\mathrm{a}_{23}\right)$ respectively. Contagion running from Hungary to the Czech Republic and Poland is also statistically significant, albeit smaller in magnitude, and equal to $0.2763\left(\mathrm{a}_{12}+\mathrm{a}^{*}{ }_{12}\right)$ and $0.1404\left(\mathrm{a}_{13}+\mathrm{a}^{*}{ }_{13}\right)$ respectively. By contrast, the magnitude of the spillovers from Poland to Hungary is not affected by the EU accession and it remains equal to 0.1754. Also, the exogenous variables considered are statistically significant for all three CEECs, the estimated coefficients indicating a negative $\delta$ (TBill interest rate) and positive $\gamma$ (US stock returns) effect, as one would expect.

\section{Conclusions}

This paper has analysed financial linkages between three CEEC countries (the Czech Republic, Hungary and Poland) using a VAR-GARCH $(1,1)$ framework. The estimated model allows distinguishing between interdependence and contagion in the form of possible effects of the EU accession on existing volatility spillovers. Whether regional financial integration has increased after May 2004 is an interesting question, as a positive finding could be plausibly interpreted as reflecting an even more significant common influence of the stock markets of the "old" EU countries. Overall, the empirical analysis provides evidence of substantial shifts in the spillover parameters after the EU accession; indeed, regional linkages appear to have become even stronger. This result is consistent with those of

\footnotetext{
${ }^{4}$ These results, not significant at the standard 5\% significance level, are not reported.
} 
Hanousek and Kocenda (2011), who, using intra-day data for the same three CEECs, found that the effects of the Frankfurt stock exchange dominate those from the US market; further, news on the EU current account affect significantly all three countries under consideration. On the whole, they conclude that macroeconomic news from the "old" EU countries have very strong effects on all three "new" EU markets.

The deeper integration within Central and Eastern Europe revealed by our analysis obviously makes portfolio diversification within the region an even less effective investment strategy, and should be taken into account by institutional investors when making their investment decisions. Also, it appears that as these markets have become more mature and integrated with the rest of the EU, their sensitivity to outside developments has increased, making their own regional linkages stronger. This has important implications for the financial stability of the region in the case of crises such as the recent one originating from the developed economies, and appropriate policy responses to such types of shocks should be carefully considered by the monetary and financial authorities of the CEECs.

Received 21 September 2011, Revised 7 November 2011, Accepted 10 November 2011

\section{References}

Bollerslev, T.P. and J.M. Wooldridge. (1992), "Quasi-maximum likelihood estimation and inference in dynamic models with time-varying covariances", Econometric Review, 11, 143-172.

Büttner, D., Hayo, B., and M. Neuenkirch. (2011), "The impact of foreign macroeconomic news on financial markets in the Czech Republic, Hungary, and Poland", Empirica, forthcoming.

Caporale, G.M. and N. Spagnolo. (2011), Stock Market Integration between three CEECs, Russia and the UK., Review of International Economics, 19(1), 158.169.

Caporale, G.M., Cipollini, A. and N. Spagnolo. (2005), "Testing for contagion: a conditional correlation analysis", Journal of Empirical Finance, 12, 3, 476-489.

Engle, R.F., and K.F. Kroner. (1995), "Multivariate simultaneous generalized ARCH", Econometric Theory, 11, 122-150.

Egert, B. and E. Koucenda. (2007), Interdependence between Eastern and Western European stock markets: evidence from intraday data, Economic Systems, 31, 184203.

Egert, B., and E. Koucenda. (2011), "Time-Varying Synchronization of the European Stock Markets", Empirical Economics, 40(2), 393-407. 
Hanousek, J., Koucenda, E. (2011), "Foreign News and Spillovers in Emerging European Stock Markets", Review of International Economics, 19(1), 170.188.

Hanousek, J., Koucenda, E., and A. Kutan. (2009), “The Reaction of Asset Prices to Macroeconomic Announcements in New EU Markets: Evidence from Intraday Data", Journal of Financial Stability, 5(2), 199-219.

Ljung, G.M. and G.E.P. Box. (1978), "On a measure of lack of .t in time series models", Biometrika, 65, 297-303. 